\title{
Development and validation of a risk score for hospitalization for heart failure in patients with Type 2 Diabetes Mellitus Xilin Yang ${ }^{\dagger}$, Ronald C Ma ${ }^{\dagger 1}$, Wing-Yee So ${ }^{1}$, Alice P Kong1,2, Gary T Ko*3, Chun-Shun $\mathrm{Ho}^{4}$, Christopher W Lam ${ }^{4}$, Clive S Cockram ${ }^{1}$, Peter C Tong1,2 and Juliana C Chan ${ }^{1,2,3}$
}

\begin{abstract}
Address: ${ }^{1}$ Department of Medicine and Therapeutics, The Chinese University of Hong Kong, Hong Kong SAR, China, ${ }^{2}$ Li Ka Shing Institute of Health Sciences, The Chinese University of Hong Kong, Hong Kong SAR, China, ${ }^{3}$ Hong Kong Institute of Diabetes and Obesity, The Chinese University of Hong Kong, Hong Kong SAR, China and ${ }^{4}$ Department of Chemical Pathology, The Chinese University of Hong Kong, Hong Kong SAR, China

Email: Xilin Yang - yang.xilin@cuhk.edu.hk; Ronald C Ma - rcwma@cuhk.edu.hk; Wing-Yee So - wingyeeso@cuhk.edu.hk; Alice P Kong - alicekong@cuhk.edu.hk; Gary T Ko* - garyko@cuhk.edu.hk; Chun-Shun Ho - csho@cuhk.edu.hk; ChristopherW Lam - cwklam@cuhk.edu.hk; Clive S Cockram - cscockram@cuhk.edu.hk; Peter C Tong - ptong@cuhk.edu.hk; Juliana C Chan - jchan@cuhk.edu.hk

* Corresponding author †Equal contributors
\end{abstract}

Published: 22 April 2008

Cardiovascular Diabetology 2008, 7:9 doi:10.1186/1475-2840-7-9

This article is available from: http://www.cardiab.com/content/7/1/9

(c) 2008 Yang et al; licensee BioMed Central Ltd.

This is an Open Access article distributed under the terms of the Creative Commons Attribution License (http://creativecommons.org/licenses/by/2.0), which permits unrestricted use, distribution, and reproduction in any medium, provided the original work is properly cited.
Received: 17 January 2008

Accepted: 22 April 2008

\begin{abstract}
Background: There are no risk scores available for predicting heart failure in Type 2 diabetes mellitus (T2DM). Based on the Hong Kong Diabetes Registry, this study aimed to develop and validate a risk score for predicting heart failure that needs hospitalisation in T2DM.

Methods: 7067 Hong Kong Chinese diabetes patients without history of heart failure, and without history and clinical evidence of coronary heart disease at baseline were analyzed. The subjects have been followed up for a median period of 5.5 years. Data were randomly and evenly assigned to a training dataset and a test dataset. Sex-stratified Cox proportional hazard regression was used to obtain predictors of HF-related hospitalization in the training dataset. Calibration was assessed using Hosmer-Lemeshow test and discrimination was examined using the area under receiver's operating characteristic curve (aROC) in the test dataset.
\end{abstract}

Results: During the follow-up, 274 patients developed heart failure event/s that needed hospitalisation. Age, body mass index (BMI), spot urinary albumin to creatinine ratio (ACR), $\mathrm{HbA} \mathrm{Ic}_{\mathrm{Ic}}$, blood haemoglobin $(\mathrm{Hb})$ at baseline and coronary heart disease during follow-up were predictors of HF-related hospitalization in the training dataset. HF-related hospitalization risk score $=0.0709$ $\times$ age $($ year $)+0.0627 \times \mathrm{BMI}\left(\mathrm{kg} / \mathrm{m}^{2}\right)+0.1363 \times \mathrm{HbA}_{\mathrm{Ic}}(\%)+0.9915 \times \log _{10}(\mathrm{I}+\mathrm{ACR})(\mathrm{mg} / \mathrm{mmol})-$ $0.3606 \times$ Blood $\mathrm{Hb}(\mathrm{g} / \mathrm{dL})+0.816 \mathrm{I} \times \mathrm{CHD}$ during follow-up (I if yes). The 5 -year probability of heart failure $=I-S_{0}(5) \operatorname{EXP}\{0.9744 \times($ Risk Score -2.3961$)\}$. Where $S_{0}(5)=0.9888$ if male and 0.9809 if female. The predicted and observed 5-year probabilities of HF-related hospitalization were similar ( $\mathrm{p}>$ 0.20 ) and the adjusted aROC was 0.920 for 5 years of follow-up.

Conclusion: The risk score had adequate performance. Further validations in other cohorts of patients with T2DM are needed before clinical use. 


\section{Background}

Besides coronary heart disease (CHD), diabetes is another major cause for hospital admissions due to heart failure (HF), which contributes to major morbidity and premature mortality in people with diabetes [1]. Subjects with Type 2 diabetes and impaired glucose regulation have 2.8fold and 1.7-fold risk of developing HF respectively, when compared to individuals with normoglycemia [2]. The Framingham Study [3] and the United Kingdom Prospective Diabetes Study (UKPDS) developed risk scores or engines to predict CHD-related events [4] and stroke [5]. Based on the Hong Kong Diabetes Registry, our group has developed and validated risk scores for predicting endstage renal disease [6,7], stroke [8], coronary heart disease [9] and all-cause mortality [10]. These risk equations may enable risk stratification for more effective preventive strategies in Chinese patients with type 2 diabetes. Notwithstanding the importance of HF in type 2 diabetes, the predictors for HF have not been fully explored.

The Hong Kong Diabetes Registry was established in 1995 as a quality assurance and continuous improvement tool with particular focus on risk stratification, treatment to targets and patient empowerment. In the present analysis, we aimed to develop and validate a risk score for predicting HF that needed hospitalization.

\section{Methods \\ Subjects}

The Prince of Wales Hospital is a regional hospital which covers a catchment area of 1.2 million residents. The Hong Kong Diabetes Registry was established in 1995 and enrols 30-50 ambulatory diabetic patients each week. The referral sources included general practitioners, community and other specialty clinics as well as patients discharged from hospitals. Enrolled patients with hospital admissions within 6-8 weeks prior to assessment accounted for less than $10 \%$ of all referrals. The 4-hour assessment of complications and risk factors was performed on an outpatient basis, modified from the European DIABCARE protocol [11]. The study was approved by the Chinese University of Hong Kong Clinical Research Ethics Committee and written informed consent was obtained from all patients. From 1995 to 2005, 7920 diabetic patients were enrolled in this Registry. Among them, 332 with Type 1 diabetes defined as acute presentation with diabetic ketoacidosis, heavy ketonuria $(>3+)$ or continuous requirement of insulin within 1 year of diagnosis, and 5 with uncertain type 1 diabetes status, were excluded from the analysis. In addition, 49 with non-Chinese or unknown nationality were excluded. In line with the UKPDS CHD risk engine [4] and our CHD risk score [9], 467 patients were also excluded due to past history of CHD or HF. A total of 7067 Chinese patients with type 2 diabetes who were free of past history of HF and CHD at enrolment were included in this analysis.

\section{Clinical outcomes}

Clinical endpoints included hospital discharge diagnoses and mortality recorded before or on $30^{\text {th }}$ July 2005 were recorded or otherwise censored on $30^{\text {th }}$ July 2005 . Details of hospital admissions were retrieved from the Hong Kong Hospital Authority Central Computer System. The latter records admissions to all public hospitals, which account for about $95 \%$ of hospital bed-days due to the heavily subsidized health care system in Hong Kong. These databases including the Hong Kong Death Registry were matched by a unique identification number, the Hong Kong Identity Card number, which is compulsory for all residents in Hong Kong. Principal hospital discharge diagnoses coded by the International Classification of Diseases Ninth Revision were used to identify HF that needed hospitalisation (Code 428). The diagnosis of HF was consistent with the recommended guidelines [12]. Follow-up time was calculated as the time from enrolment to the first hospitalization for HF, death or $30^{\text {th July }}$ 2005.

\section{Clinical measurements}

Details of assessment methods and definitions have been previously described $[6,8-10,13]$. On the day of assessment, patients attended the centre after 8 hours of fasting and underwent anthropometric measurements and laboratory investigations. Apart from documentation of demographic data and clinical assessment of complications, fasting blood samples were taken for measurement of plasma glucose, glycosylated haemoglobin $\left(\mathrm{HbA}_{1 \mathrm{c}}\right)$, lipid profile (total cholesterol, high density lipoprotein cholesterol and triglycerides, calculated low density lipoprotein cholesterol, renal and liver functions. A sterile, random spot urine sample was used to measure albumin creatinine ratio (ACR). Peripheral arterial disease was defined by lower limb amputation, the absence of foot pulses on palpation, confirmed by an ankle:brachial ratio $\leq 0.90$ as measured by Doppler ultrasound examination, or history of revascularization for peripheral arterial disease. This study used the abbreviated Modification of Diet in Renal Disease (MDRD) formula re-calibrated for Chinese [14] to estimate glomerular filtration rate (eGFR) expressed in $\mathrm{ml} \mathrm{min}^{-1} 1.73 \mathrm{~m}^{-2}$ : eGFR $=186 \times$ [SCR $\times$ $0.011]^{-1.154} \times$ [age $]^{-0.203} \times[0.742$ if female $] \times 1.233$, where $\mathrm{SCR}$ is serum creatinine expressed as $\mu \mathrm{mol} / \mathrm{l}$ (original $\mathrm{mg} /$ $\mathrm{dL}$ converted to $\mu \mathrm{mol} / \mathrm{l}$ ) and 1.233 is the adjusting coefficient for Chinese ethnicity. Laboratory assays have also been described previously [6].

\section{Statistical analyses}

The Statistical Analysis System (Release 9.10) was used to perform the statistical analysis (SAS Institute Inc., Cary, 
USA). Split-half validation was used to develop the risk score. The dataset was randomly divided into two datasets using a computer-generated random number: the training dataset for model development and the test dataset for validation of the developed HF risk score. In the training dataset, Cox proportional regression analysis with the backward algorithm ( $\mathrm{p}<0.05$ for stay) was used to select predictors of HF. The candidate baseline variables for inclusion in the final model included age, sex, current and ex smoker status, duration of diabetes, systolic blood pressure, glycated haemoglobin $\left(\mathrm{HbA}_{1 \mathrm{c}}\right)$, body mass index (BMI), blood haemoglobin (Hb), white blood cell count, high density lipoprotein cholesterol, low density lipoprotein cholesterol, triglyceride, non-high density lipoprotein cholesterol, spot urinary ACR, eGFR, sensory neuropathy, retinopathy, peripheral arterial disease, history of stroke, and drug use variables (lipid-lowering drugs and angiotensin-converting enzyme (ACE) inhibitors or angiotensin II receptor blockers (ARB), diet treatment, oral anti-diabetic drugs, other antihypertensive drugs, and insulin at enrolment). As CHD is an important risk predictor of HF [15], we added an additional variable that recorded CHD events during follow-up period [9] to improve the predicting ability of the HF risk score. Proportional hazards assumption and functional form were checked using Supremum test [16].

Construction of risk scores and probability equations from Cox models have been described previously $[8,9]$. The shrinkage factor was calculated using (LR-p)/LR, where LR denotes the likelihood ratio $\chi^{2}$ and $\mathrm{p}$ the number of the predictors in the final model (below 0.85 raises concern of over-fitting) [17].

Validation of the risk score was performed using the test dataset. Calibration was checked using the Hosmer and Lemeshow test [10]. Overall discrimination was checked by $\mathrm{C}$ index as calculated by Pencina's method [18]. The 5year discrimination as indicated by the area under receiver operating characteristic curve, as well as the 5-year sensitivity and specificity were calculated using Chambless' method [19]. A p value $<0.05$ was considered to be statistically significant.

\section{Results}

\section{Characteristics of study population}

At enrolment, the median age of the cohort was 57 years (interquartile range, IQR: 46-67 years) and the median duration of diabetes was 5 (IQR: 1-11) years. During a median follow-up period of 5.52 years (IQR: $2.90-7.87$ years), $3.32 \%(\mathrm{n}=274)$ of patients had HF that needed hospitalisation, giving an incident rate of 7.17 (95\% CI: 6.33-8.02) per 1000 person-years. During the follow-up period, 681 patients died. Other population characteristics are listed in Table 1. In the training dataset, compared to patients without hospitalisation for HF, those with hospitalisation for HF had older age (median/IQR 69/13 vs. $56 / 20$ years, $\mathrm{p}<0.0001)$, higher $\mathrm{HbA}_{1 \mathrm{c}}(7.8 / 2.6$ vs. $6.7 /$ $2.1 \%, \mathrm{p}<0.0001)$, higher ACR $(52.5 / 230.7$ vs. $1.9 / 8.4$ $\mathrm{mg} / \mathrm{mmol}, \mathrm{p}<0.0001)$, lower blood $\mathrm{Hb}$ (12.5/2.6 vs. $13.9 / 2.1 \mathrm{~g} / \mathrm{dL}, \mathrm{p}<0.0001)$ and longer duration of diabetes $(10 / 11$ vs. $5 / 9$ years, $\mathrm{p}<0.0001)$ but had similar BMI $\left(24.7 / 4.9\right.$ vs. $\left.24.7 / 4.8 \mathrm{~kg} / \mathrm{m}^{2}, \mathrm{p}=0.5021\right)$.

\section{Predicting models}

In the training dataset, age, sex, $\mathrm{BMI}, \mathrm{HbA}_{1 c^{\prime}} \log _{10}$ $(\mathrm{ACR}+1)$ and blood $\mathrm{Hb}$ at baseline and $\mathrm{CHD}$ event during follow-up were selected by the model as predictors for HFrelated hospitalisation. The functional forms of age, BMI, $\mathrm{HbA}_{1 \mathrm{C}^{\prime}} \log _{10}(\mathrm{ACR}+1)$ and $\mathrm{Hb}$ seem adequate $(\mathrm{p}>0.40)$. All the predictors apart from sex $(\mathrm{p}<0.0001)$ did not violate the proportional hazards assumption $(\mathrm{p}>0.20)$. To correct for violation of proportional hazards assumption in sex ( $p=0.0080)$, sex-stratified Cox model was used to derive $\beta$ and hazard ratio estimates of age, $\mathrm{BMI}, \mathrm{HbA}_{1 \mathrm{c}^{\prime}}$ $\log _{10}(\mathrm{ACR}+1)$ and blood $\mathrm{Hb}$ at baseline and CHD during follow-up. Their hazard ratios (both univariate and multivariate analyses), $\beta$ coefficients and 95\% confidence intervals (CI) are listed in Table 2. Over-fitting of the final predicting model is, if any, very small (the shrinkage = 0.9744).

Based on the values of $\beta$ coefficients, the risk score and 5year probability of HF that needs hospitalisation are constructed as follows:

HF-related hospitalization risk score $=0.0709 \times$ age $($ year $)$ $+0.0627 \times \mathrm{BMI}\left(\mathrm{kg} / \mathrm{m}^{2}\right)+0.1363 \times \mathrm{HbA}_{1 \mathrm{c}}(\%)+0.9915 \times$ $\log _{10}(1+\mathrm{ACR})(\mathrm{mg} / \mathrm{mmol})-0.3606 \times$ Blood Hb $(\mathrm{g} / \mathrm{dL})+$ $0.8161 \times$ CHD during follow-up ( 1 if yes).

The 5-year probability of heart failure $\left.=1-\mathrm{S}_{0}(5)\right)^{\operatorname{EXP}\{0.9744 \times}$ (Risk Score - 2.3961) $\}$, where $S_{0}(5)=0.9888$ if male and 0.9809 if female.

\section{Validation of risk equations}

In the test dataset, the predicted probability of HF-related hospitalisation over 5 years of follow-up was not significantly different from the observed probability of HFrelated hospitalisation probability $(\mathrm{p}>0.20)$ (Figure 1$)$. The overall C index (for overall discrimination) was 0.853 (95\% CI: 0.819-0.886). The follow-up time and censoring status adjusted aROC for 5 years of follow-up was 0.920 . Using the cut-off point of $\geq 3.4683$ for the risk score, the sensitivity was $90.5 \%$ and the specificity was $75.6 \%$. If the cut-off point of 4.5334 was used, the sensitivity decreased to $71.1 \%$ while the specificity increased to $90.4 \%$. Sensitivities and specificities of other cut-off points are listed in Table 3. 
Table I: Baseline clinical and biochemical characteristics of 7074 Chinese Type 2 diabetic patients without clinical evidence of coronary heart disease and heart failure at enrollment during $\mathbf{5 . 5 2}$ years of follow-up in the training dataset and the test dataset

\begin{tabular}{|c|c|c|c|c|}
\hline & \multicolumn{2}{|c|}{ Training dataset $(n=3456)$} & \multicolumn{2}{|c|}{ Test dataset $(\mathrm{n}=361 \mathrm{I})$} \\
\hline & median or $\%$ & IQR* & median or $\%$ & IQR* \\
\hline Male Gender & $45.2 \%$ & & $45.6 \%$ & \\
\hline \multicolumn{5}{|l|}{ Smoking status } \\
\hline Current smoker & $20.4 \%$ & & $20.7 \%$ & \\
\hline Ex smoker & $13.1 \%$ & & $13.8 \%$ & \\
\hline Age (year) & 57 & 21 & 57 & 21 \\
\hline Body mass index $\left(\mathrm{kg} / \mathrm{m}^{2}\right)$ & 24.6 & 4.8 & 24.7 & 5.0 \\
\hline Years of diagnosed diabetes & 5 & 10 & 5 & 9 \\
\hline Systolic BP (mmHg) & 134 & 27 & 134 & 28 \\
\hline Diastolic BP (mmHg) & 76 & 13 & 76 & 15 \\
\hline $\mathrm{HbA}_{\mathrm{Ic}}(\%)$ & 7.3 & 2.2 & 7.4 & 2.2 \\
\hline Blood haemoglobin $(g / L)$ & 13.8 & 2.1 & 13.8 & 2.2 \\
\hline White blood cell count (10\%/counts/L) & 7.0 & 2.4 & 7.0 & 2.4 \\
\hline Spot urinary albumin creatinine ratio $(\mathrm{mg} / \mathrm{mmol})$ & 2.0 & 10.1 & 2.0 & 10.0 \\
\hline $\operatorname{eGFR}\left(\mathrm{ml} \mathrm{min}-11.73 \mathrm{~m}^{-2}\right) \xi$ & 104.9 & 43.0 & 104.9 & 43.5 \\
\hline LDL-C (mmol/l) & 3.13 & 1.24 & 3.11 & 1.29 \\
\hline $\mathrm{HDL}-\mathrm{C}(\mathrm{mmol} / \mathrm{l})$ & 1.24 & 0.45 & 1.25 & 0.45 \\
\hline Triglyceride (mmol/L) & 1.37 & 1.08 & 1.39 & 1.12 \\
\hline Non-HDL cholesterol (mmol/L) & 3.87 & 1.40 & 3.87 & 1.43 \\
\hline \multicolumn{5}{|l|}{ Drug use at baseline } \\
\hline On diet treatment & $10.2 \%$ & & $9.9 \%$ & \\
\hline Use of oral anti-diabetic drugs & $61.0 \%$ & & $60.6 \%$ & \\
\hline Use of anti-hypertensive drugs & $34.1 \%$ & & $33.3 \%$ & \\
\hline Use of insulin & $17.5 \%$ & & $17.4 \%$ & \\
\hline Use of LLD§ & $11.6 \%$ & & $13.2 \%$ & \\
\hline Use of ACEl or ARBT & $20.4 \%$ & & $20.1 \%$ & \\
\hline \multicolumn{5}{|l|}{ Complications at baseline } \\
\hline Retinopathy & $25.4 \%$ & & $27.4 \%$ & \\
\hline Sensory neuropathy & $26.0 \%$ & & $25.7 \%$ & \\
\hline Peripheral arterial disease & $5.8 \%$ & & $5.9 \%$ & \\
\hline History of stroke & $3.6 \%$ & & $4.4 \%$ & \\
\hline \multicolumn{5}{|l|}{ Complications during follow-up } \\
\hline Coronary heart disease before heart failure during follow-up & $4.4 \%$ & & $4.4 \%$ & \\
\hline Heart failure hospitalisation during follow-up & $3.8 \%$ & & $4.0 \%$ & \\
\hline Death during follow-up & $9.4 \%$ & & $9.9 \%$ & \\
\hline
\end{tabular}

*, Median (IQR = interquartile range); $\xi$, eGFR = estimated glomerular filtration rate; §, LLD, lipid lowering drugs; $\uparrow$, ACEI, Angiotensin-converting enzyme inhibitors and ARB for angiotensin II receptor blockers.

\section{Discussion}

In this analysis, we demonstrated that HF that needed hospitalisation can be predicted with good accuracy in type 2 diabetes. Using 7 commonly collected variables: age, sex, BMI, $\mathrm{HbA}_{1 \mathrm{c}}$ ACR and blood $\mathrm{Hb}$, the risk score can provide absolute risks of hospitalisation for $\mathrm{HF}$, which depends on whether CHD event/s occurs or not in a 5-year period. The risk score has achieved an excellent discriminatory power of 0.920 for predicting hospitalisation due to HF over a 5 -year period in type 2 diabetic patients while maintaining adequate calibration.

The discrimination of a risk score determines the efficacy and thus usefulness of a risk score. Several risk scores have been published for predicting hard CHD events, i.e. nonfatal myocardial infarction and fatal CHD events, in both general and type 2 diabetic populations. The Framingham CHD risk score has an C-statistics of 0.79 for men and 0.83 for women in their original population and $0.63-$ 0.75 for men and $0.66-0.83$ for women in other USA populations [20]. Liu et al [21] validated the Framingham risk score in a general Chinese population and the re-calibrated risk score had an aROC of 0.71 for Chinese men and 0.74 for Chinese women. The UKPDS risk engine for hard CHD endpoints did not report any measures of discrimination in the original report [4]. A validation study in a UK type 2 diabetic population by Guzder et al [22] reported that the UKPDS CHD risk engine had a discrimination of 0.67 for C-statistics. Donnan et al [23] developed a risk score for major CHD in type 2 diabetes population with a discrimination score of 0.71 in the original dataset and 0.69 in an independent dataset. Another 
Table 2: Parameter estimates of the risk score for heart failure hospitalisation in the training dataset.

\begin{tabular}{|c|c|c|c|c|c|c|}
\hline \multirow[b]{2}{*}{ Variablest } & \multicolumn{2}{|c|}{ Univariate Analysis } & \multicolumn{4}{|c|}{ Multivariate Analysis } \\
\hline & Hazard ratio $(95 \% \mathrm{Cl})$ & $P$ value & Estimates of $\beta$ values & S.E.M & Hazard ratio $(95 \% \mathrm{Cl})$ & $P$ value \\
\hline \multicolumn{7}{|l|}{ Variables used in the predicting model } \\
\hline Age, per year & $1.10(1.08-1.12)$ & $<.0001$ & 0.0709 & 0.0107 & $1.07(1.05-1.10)$ & $<.0001$ \\
\hline Body mass index, per kg/m² & $1.01(0.97-1.05)$ & 0.6568 & 0.0627 & 0.0286 & $1.07(1.01-1.13)$ & 0.0282 \\
\hline Glycated haemoglobin, per \% & $1.16(1.07-1.25)$ & 0.0003 & 0.1363 & 0.0550 & $1.15(1.03-1.28)$ & 0.0132 \\
\hline $\begin{array}{l}\log _{10}(I+\text { spot urinary albumin to creatinine } \\
\text { ratio, per } \mathrm{mg} / \mathrm{mmol})\end{array}$ & $4.50(3.65-5.54)$ & $<.0001$ & 0.9915 & 0.1409 & $2.70(2.32-3.55)$ & $<.0001$ \\
\hline Blood haemoglobin, per g/dL & $0.61(0.55-0.68)$ & $<.0001$ & -0.3606 & 0.0684 & $0.70(0.6 \mathrm{I}-0.80)$ & 0.0001 \\
\hline $\begin{array}{l}\text { Coronary heart disease during follow-up ( } 1 \text {. } \\
\text { yes, } 0 . \text { no) }\end{array}$ & $3.6 I(2.24-5.8 I)$ & $<.0001$ & 0.8161 & 0.2675 & $2.26(1.26-4.05)$ & 0.0061 \\
\hline \multicolumn{7}{|l|}{ Variables not used in the predicting model } \\
\hline Duration of diabetes, per year & $1.07(1.05-1.09)$ & $<.0001$ & & & Not selected & \\
\hline $\begin{array}{l}\text { Glomerular filtration rate, } \mathrm{per} \mathrm{ml} \mathrm{min} \mathrm{min}^{-1} 1.73 \mathrm{~m}^{-} \\
\text {- }\end{array}$ & $0.97(0.96-0.97)$ & $<.0001$ & & & Not selected & \\
\hline Systolic blood pressure, per mmHg & $1.03(1.02-1.04)$ & $<.0001$ & & & Not selected & \\
\hline Diastolic blood pressure, per $\mathrm{mmHg}$ & $1.01(0.99-1.02)$ & 0.5640 & & & Not selected & \\
\hline $\begin{array}{l}\text { Low density lipoprotein cholesterol, per } \\
\mathrm{mmol} / \mathrm{L}\end{array}$ & $1.12(0.94-1.33)$ & 0.2155 & & & Not selected & \\
\hline $\begin{array}{l}\text { High density lipoprotein cholesterol, per } \\
\mathrm{mmol} / \mathrm{L}\end{array}$ & $0.80(0.48-1.34)$ & 0.3976 & & & Not selected & \\
\hline Triglyceride, per mmol/L & $1.04(0.96-1.12)$ & 0.3665 & & & Not selected & \\
\hline Smoking status & & & & & Not selected & \\
\hline Current smokers & $0.62(0.37-1.02)$ & 0.0592 & & & & \\
\hline Ex-smokers & $1.96(1.28-3.01)$ & 0.0020 & & & & \\
\hline Never & 1.0 & & & & & \\
\hline Use of oral anti-diabetic drugs at baseline & $1.04(0.73-1.47)$ & 0.8471 & & & Not selected & \\
\hline Use of anti-hypertensive drugs at baseline & $3.98(2.79-5.67)$ & $<.0001$ & & & Not selected & \\
\hline Use of LLD at baseline & $1.88(1.16-3.09)$ & 0.0112 & & & Not selected & \\
\hline Use of ACEI or ARB at baseline & $2.44(1.66-3.59)$ & $<.0001$ & & & Not selected & \\
\hline Use of insulin at baseline & $3.59(2.52-5.10)$ & $<.0001$ & & & Not selected & \\
\hline
\end{tabular}

t, Sex-stratified Cox model was used to obtain estimates of $\beta$ values and hazard rato of predctors for heart failure. $\chi^{2}$ test for likelihood ratio test $=234.60$, Degree of freedom $=6, p<0.000 \mathrm{I}$ and the shrinkage of the model is $=(234.60-6) / 274.66=0.9744$; Not selected indiates not selected by the backward algorithm at the significant levelt of 0.05 .

$\mathrm{Cl}$, confidence interval; LLD, lipid lowering drugs; ACEI, Angiotensin-converting enzyme inhibitors; ARB, angiotensin II receptor blockers

risk score which predicted cardiovascular events and mortality using clinical predictors and baseline dobutamine stress echocardiography reported C-statistics values of 0.60 and 0.64 respectively [24]. Thus, a discriminatory power of $\mathrm{C}$ index 0.85 and aROC 0.92 of the current HFrelated hospitalisation risk score indicates an excellent performance in distinguishing between those who would need hospitalisation for HF from their counterparts who would not. Comparing this risk score with other risk scores that were derived from the same cohort, the risk score has better discriminatory power than CHD (aROC: 0.74 ) [9], stroke (aROC: 0.77) [8] and all-cause mortality (aROC: 0.85 ) risk scores [10] but poorer discriminatory power than end stage renal disease risk score (aROC > $0.94)[6,7]$. Similarly, the calibration is also adequate, better than the CHD risk score[9]but poorer than the allcause mortality risk score [10].

Besides the CHD status on follow-up, the risk scores included as few as 6 baseline variables: age, BMI, $\mathrm{HbA}_{1 \mathrm{c}^{\prime}}$
ACR, blood Hb and sex. Most of these parameters have been verified to be associated with HF in other studies. $\mathrm{HbA}_{1 \mathrm{c}}$ has been repeatedly found to be associated with increased risk of HF $[1,25]$. Low hematocrit and Hb levels have recently emerged as a major promoter of cardiovascular morbidity and mortality [26]. In agreement with Horwich et al [27] who reported association of anemia with early mortality in patients with advanced HF, we found that blood $\mathrm{Hb}$ had a strong independent predictive effect in the present cohort. Low Hb level can cause HF via many mechanisms including tissue hypoxia and left ventricular failure [28]. Several studies have now confirmed the strong risk association between albuminuria and HF in patients with type 2 diabetes [29-31]. Hockensmith et al [30] reported that baseline albuminuria was independently associated with 5.4 fold increased odds ratio of hospitalizations due to $\mathrm{HF}(95 \% \mathrm{CI}: 2.3-12.5)$. In the Angiotensin II Antagonist Losartan Trial which recruited 1513 type 2 diabetic patients with nephropathy, high baseline albuminuria was associated with a 2.70 -fold risk 
Table 3: Sensitivity, specificity, positive predictive values at selected risk scores and the probability of heart failure over 5 years of follow-up in the test dataset

\begin{tabular}{|c|c|c|c|c|c|c|}
\hline \multirow[t]{2}{*}{ Risk score cutoff point* } & \multicolumn{2}{|c|}{ Predicted probability of heart failure } & \multirow[t]{2}{*}{ Sensitivity } & \multirow[t]{2}{*}{ Specificity } & \multirow[t]{2}{*}{ Positive predictive value } & \multirow[t]{2}{*}{ Negative predictive value } \\
\hline & Women & Men & & & & \\
\hline 2.5606 & 0.0131 & 0.0129 & 0.980 & 0.571 & 0.429 & 0.086 \\
\hline 3.0776 & 0.0216 & 0.0213 & 0.954 & 0.685 & 0.315 & 0.111 \\
\hline 3.3153 & 0.0272 & 0.0267 & 0.929 & 0.726 & 0.274 & 0.122 \\
\hline $3.4683 \dagger$ & 0.0315 & 0.0310 & 0.905 & 0.756 & 0.244 & 0.132 \\
\hline 3.5859 & 0.0353 & 0.0346 & 0.896 & 0.777 & 0.223 & 0.142 \\
\hline 3.6385 & 0.0371 & 0.0364 & 0.883 & 0.786 & 0.214 & 0.145 \\
\hline 3.9032 & 0.0477 & 0.0469 & 0.873 & 0.827 & 0.173 & 0.172 \\
\hline 3.9644 & 0.0506 & 0.0497 & 0.851 & 0.837 & 0.163 & 0.177 \\
\hline 4.1012 & 0.0576 & 0.0566 & 0.831 & 0.857 & 0.143 & 0.193 \\
\hline 4.2309 & 0.0651 & 0.0640 & 0.821 & 0.877 & 0.123 & 0.216 \\
\hline 4.3201 & 0.0708 & 0.0696 & 0.786 & 0.887 & 0.113 & 0.222 \\
\hline 4.4208 & 0.0778 & 0.0765 & 0.727 & 0.894 & 0.106 & 0.220 \\
\hline $4.5334 \dagger$ & 0.0864 & 0.0849 & 0.711 & 0.904 & 0.096 & 0.234 \\
\hline 4.6189 & 0.0936 & 0.0920 & 0.698 & 0.914 & 0.086 & 0.250 \\
\hline 4.7414 & 0.1048 & 0.1030 & 0.662 & 0.923 & 0.077 & 0.261 \\
\hline 4.8633 & 0.1172 & 0.1152 & 0.607 & 0.931 & 0.069 & 0.266 \\
\hline 5.0962 & 0.1448 & 0.1424 & 0.551 & 0.950 & 0.050 & 0.311 \\
\hline 5.4119 & 0.1916 & 0.1886 & 0.437 & 0.966 & 0.034 & 0.345 \\
\hline
\end{tabular}

*, Calculated using the risk score equation; **, Calculated using the 5-year heart failure probability; $\dagger$, The suggested cutoff points.

for HF compared with patients with low levels of albuminuria and that reduction of ACR at 6 months post treatment including the use of ARB predicted reduced risk of new onset of HF [32]. A study reported that BMI was not a significant predictor for mortality in patients with advanced HF [33]. In our analysis, BMI was also not a significant predictor of $\mathrm{HF}$ on univariable analysis but became significant after adjustment for $\mathrm{Hb}$. Close associ-

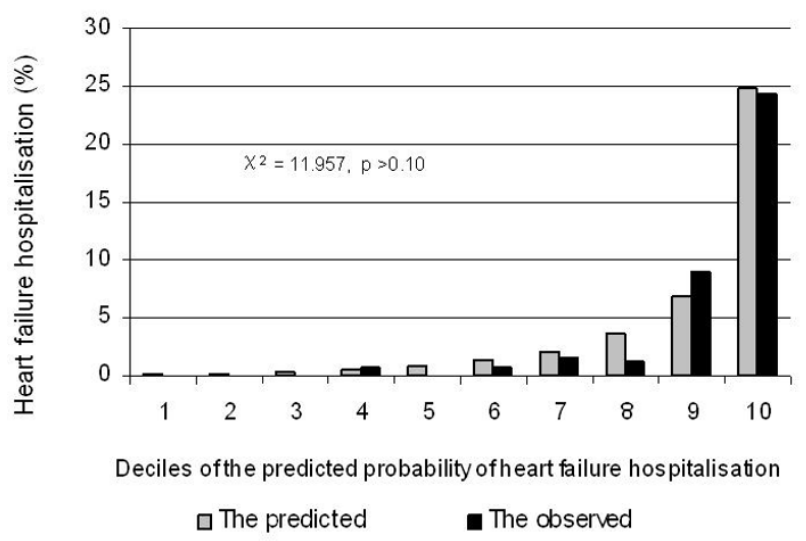

Figure I

The predicted probability of heart failure that needed hospitalisation versus the observed probability over 5 years of follow-up in the test dataset. ations between high blood $\mathrm{Hb}$, hyperviscosity syndrome and obesity [34] may mask the true increased risk of high $\mathrm{BMI}$ if blood $\mathrm{Hb}$ was not adjusted.

The risk score used future CHD events as a "predictor". The future event is unknown at the time of prediction. Nevertheless, the CHD absolute risk can be estimated using the CHD risk score developed from the same cohort[9], using age, sex, current smoking status, duration of diabetes, non high density lipoprotein cholesterol, ACR and eGFR. In the UKPDS, both CHD and stroke risk engines were used in the case mortality risk engine to estimate the absolute risk of case mortality of patients who subsequently developed CHD or stroke event [35]. Similarly, our CHD risk score can also be used in the risk score to estimate the absolute risk of hospitalization for HF.

\section{Limitations}

First, similar to another study [29], we used the definition of hospitalisation for HF rather than HF itself. The possibility underestimating severe HF incidence using this definition should be very small since Hong Kong Government maintains a heavily subsidised health care system and severe HF without being hospitalised are most unlikely. Second, although the registry is not populationbased, due to the lack of a comprehensive health insurance policy and integrated primary health care system in Hong Kong, majority of patients in patients with chronic diseases such as diabetes and heart disease are managed in public hospitals. In 2000, Department of Health of Hong 
Kong conducted a survey and reported that over $90 \%$ of patients diagnosed with diabetes were managed in the public health sector [10]. Third, our cohort of type 2 diabetic patients had a wide range of disease duration which may theoretically widen the $95 \%$ CI of parameter estimations. On the other hand, it is the heterogeneity that extends usefulness of this risk score from predicting HF hospitalization at diagnosis to predicting HF hospitalisation during long-term care of patients with type 2 diabetes, i.e. the risk score can be used periodically during chronic care management.

\section{Conclusion and Implications}

To our knowledge, this is the first risk score developed to predict HF events in a type 2 diabetic cohort. Given the rising prevalence of type 2 diabetes [36] and the high risk of morbidity and mortality of HF, especially in patients with diabetes [1], a risk score with such excellent performance, should enable clinicians to identify high risk subjects for intensive monitoring and treatment. Hence, validation of the risk score in other populations will be of public health importance.

\section{Abbreviations}

ACEI: Angiotensin-converting enzyme inhibitor; ACR: Albumin: creatinine ratio; ARB: angiotensin II receptor blockers; aROC: Area under receiver operating characteristic curve; BMI: Body mass index; CHD: Coronary heart disease; eGFR: Estimated glomerular filtration rate; $\mathrm{Hb}$ : Haemoglobin; $\mathrm{HbA}_{1 \mathrm{c}}$ : Glycated haemoglobin; HF: Heart failure; HR: Hazard ratio; UKPDS: United Kingdom Prospective Diabetes Study; SCR: Serum creatinine.

\section{Competing interests}

The authors declare that they have no completing interests.

\section{Authors' contributions}

$\mathrm{XY}$ performed the statistical analysis and drafted the manuscript. JC, RM, WS, GK, AK, CC and PT were involved in study design, coordination, data acquisition and manuscript revision. CL and $\mathrm{CH}$ facilitated retrieval of laboratory data and clinical outcomes. All authors have read and approved the final manuscript.

\section{Acknowledgements}

This study was supported by the Hong Kong Foundation for Research and Development in Diabetes, the Hong Kong Institute of Diabetes and Obesity, Asia Diabetes Foundation and the Li Ka Shing Institute of Health Sciences, the Chinese University of Hong Kong. We thank all medical and nursing staff of the Prince of Wales Hospital Diabetes Centre in recruiting and managing these patients.

\section{References}

I. Nichols GA, Koro CE, Gullion CM, Ephross SA, Brown JB: The incidence of congestive heart failure associated with antidiabetic therapies. Diabetes Metab Res Rev 2005, 2 I (I):5I-57.
2. Thrainsdottir IS, Aspelund T, Thorgeirsson G, Gudnason V, Hardarson T, Malmberg K, Sigurdsson G, Ryden L: The association between glucose abnormalities and heart failure in the population-based Reykjavik study. Diabetes Care 2005, 28(3):6|2-6|6.

3. Anderson KM, Odell PM, Wilson PW, Kannel WB: Cardiovascular disease risk profiles. Am Heart J 199I, I 2 I ( I Pt 2):293-298.

4. Stevens RJ, Kothari V, Adler AI, Stratton IM: The UKPDS risk engine: a model for the risk of coronary heart disease in Type II diabetes (UKPDS 56). Clin Sci (Lond) 200I, $101(6): 67 \mid-679$.

5. Kothari V, Stevens RJ, Adler Al, Stratton IM, Manley SE, Neil HA, Holman RR: UKPDS 60: risk of stroke in type 2 diabetes estimated by the UK Prospective Diabetes Study risk engine. Stroke 2002, 33(7): |776-|78|

6. Yang XL, So WY, Kong AP, Clarke P, Ho CS, Lam CW, Ng MH, Lyu RR, Yin DD, Chow CC, Cockram CS, Tong PC, Chan JC: End-stage renal disease risk equations for Hong Kong Chinese patients with type 2 diabetes: Hong Kong Diabetes Registry. Diabetologia 2006, 49(1 0):2299-2308.

7. Yang XL, So WY, Kong AP, Ho CS, Lam CW, Ng MH, Lyu RR, Yin DD, Chow CC, Cockram CS, Tong PC, Chan JC: Modified endstage renal disease risk score for Chinese type 2 diabetic patients--the Hong Kong Diabetes Registry. Diabetologia 2007, 50(6): $1348-1350$.

8. Yang X, So WY, Kong AP, Ho CS, Lam CW, Stevens RJ, Lyu RR, Yin DD, Cockram CS, Tong PC, Wong V, Chan JC: Development and validation of stroke risk equation for Hong Kong Chinese patients with type 2 diabetes: the Hong Kong Diabetes Registry. Diabetes Care 2007, 30(I):65-70.

9. Yang X, So WY, Kong AP, Ma RC, Ko GT, Ho CS, Lam CW, Cockram CS, Chan JC, Tong PC: Development and validation of a total coronary heart disease risk score in type 2 diabetes mellitus. Am J Cardiol 2008, I 0 I(5):596-60I.

10. Yang X, So WY, Tong PC, Ma RC, Kong AP, Lam CW, Ho CS, Cockram CS, Ko GT, Chow CC, Wong VC, Chan JC: Development and validation of an all-cause mortality risk score in type 2 diabetes. Arch Intern Med 2008, 168(5):45I-457.

II. Piwernetz K, Home PD, Snorgaard O, Antsiferov M, Staehr-Johansen K, Krans M: the DIABCARE Monitoring Group of the St. Vincent Declaration Steering Committee: Monitoring the targets of the St. Vincent Declaration and the implementation of quality management in diabetes care: the DIABCARE initiative. Diabet Med 1993, 10:37I-377.

12. Hunt SA, Abraham WT, Chin MH, Feldman AM, Francis GS, Ganiats TG, Jessup M, Konstam MA, Mancini DM, Michl K, Oates JA, Rahko PS, Silver MA, Stevenson LW, Yancy CW, Antman EM, Smith SC Jr., Adams CD, Anderson JL, Faxon DP, Fuster V, Halperin JL, Hiratzka LF, Jacobs AK, Nishimura R, Ornato JP, Page RL, Riegel B: ACC/ AHA 2005 Guideline Update for the Diagnosis and Management of Chronic Heart Failure in the Adult: a report of the American College of Cardiology/American Heart Association Task Force on Practice Guidelines (Writing Committee to Update the 200I Guidelines for the Evaluation and Management of Heart Failure): developed in collaboration with the American College of Chest Physicians and the International Society for Heart and Lung Transplantation: endorsed by the Heart Rhythm Society. Circulation 2005, I I 2(I 2): el54-235

13. Yang X, Ma RC, So WY, Ko GT, Kong AP, Lam CW, Ho CS, Cockram CS, Wong VC, Tong PC, Chan JC: Impacts of chronic kidney disease and albuminuria on associations between coronary heart disease and its traditional risk factors in type 2 diabetic patients - the Hong Kong diabetes registry. Cardiovasc Diabetol 2007, 6:37.

14. Ma YC, Zuo L, Chen JH, Luo Q, Yu XQ, Li Y, Xu JS, Huang SM, Wang LN, Huang W, Wang M, Xu GB, Wang HY: Modified glomerular filtration rate estimating equation for Chinese patients with chronic kidney disease. J Am Soc Nephrol 2006, I 7( I 0):2937-2944.

15. Ingelsson E, Arnlov J, Sundstrom J, Zethelius B, Vessby B, Lind L: Novel metabolic risk factors for heart failure. J Am Coll Cardiol 2005, 46( I I):2054-2060.

16. Lin DY, Wei LJ, Ying Z: Checking the Cox Model with Cumulative Sums of Martingale-Based Residuals. Biometrika 1993, 80(3):557-572 
17. Harrell FE Jr., Lee KL, Mark DB: Multivariable prognostic models: issues in developing models, evaluating assumptions and adequacy, and measuring and reducing errors. Stat Med 1996, I 5(4):36I-387.

18. Pencina MJ, D'Agostino RB: Overall $C$ as a measure of discrimination in survival analysis: model specific population value and confidence interval estimation. Stat Med 2004, 23(13):2109-2123.

19. Chambless LE, Diao G: Estimation of time-dependent area under the ROC curve for long-term risk prediction. Stat Med 2006, 25(20):3474-3486.

20. D'Agostino RB Sr., Grundy S, Sullivan LM, Wilson P: Validation of the Framingham coronary heart disease prediction scores: results of a multiple ethnic groups investigation. JAMA 200I, 286(2): $180-187$

21. Liu J, Hong Y, D'Agostino RB Sr., Wu Z, Wang W, Sun J, Wilson PW, Kannel WB, Zhao D: Predictive value for the Chinese population of the Framingham CHD risk assessment tool compared with the Chinese Multi-Provincial Cohort Study. JAMA 2004, 29 I(2I):259I-2599.

22. Guzder RN, Gatling W, Mullee MA, Mehta RL, Byrne CD: Prognostic value of the Framingham cardiovascular risk equation and the UKPDS risk engine for coronary heart disease in newly diagnosed Type 2 diabetes: results from a United Kingdom study. Diabet Med 2005, 22(5):554-562.

23. Donnan PT, Donnelly L, New JP, Morris AD: Derivation and validation of a prediction score for major coronary heart disease events in a U.K. type 2 diabetic population. Diabetes Care 2006 29(6): $123|-| 236$.

24. Chaowalit N, Arruda AL, McCully RB, Bailey KR, Pellikka PA: Dobutamine stress echocardiography in patients with diabetes mellitus: enhanced prognostic prediction using a simple risk score. J Am Coll Cardiol 2006, 47(5): 1029-1036.

25. Stratton IM, Adler Al, Neil HA, Matthews DR, Manley SE, Cull CA Hadden D, Turner RC, Holman RR: Association of glycaemia with macrovascular and microvascular complications of type 2 diabetes (UKPDS 35): prospective observational study. BMJ 2000, 32 I (7258):405-4I2.

26. Tong PC, Kong AP, So WY, Ng MH, Yang X, Ng MC, Ma RC, Ho CS, Lam CW, Chow CC, Cockram CS, Chan JC: Hematocrit, independent of chronic kidney disease, predicts adverse cardiovascular outcomes in chinese patients with type 2 diabetes. Diabetes Care 2006, 29(I I):2439-2444.

27. Horwich TB, Fonarow GC, Hamilton MA, MacLellan WR, Borenstein !: Anemia is associated with worse symptoms, greater impairment in functional capacity and a significant increase in mortality in patients with advanced heart failure. J Am Coll Cardiol 2002, 39(II): 1780-I786.

28. Metivier F, Marchais SJ, Guerin AP, Pannier B, London GM: Pathophysiology of anaemia: focus on the heart and blood vessels. Nephrol Dial Transplant 2000, I5 Suppl 3:14-I8.

29. Carr AA, Kowey PR, Devereux RB, Brenner BM, Dahlof B, Ibsen H, Lindholm LH, Lyle PA, Snapinn SM, Zhang Z, Edelman JM, Shahinfar S: Hospitalizations for new heart failure among subjects with diabetes mellitus in the RENAAL and LIFE studies. Am J Cardiol 2005, 96(II): I530-I536.

30. Hockensmith ML, Estacio RO, Mehler P, Havranek EP, Ecder ST, Lundgren RA, Schrier RW: Albuminuria as a predictor of heart failure hospitalizations in patients with type 2 diabetes. J Card Fail 2004, 10(2): |26-|3|.

31. Vaur L, Gueret P, Lievre M, Chabaud S, Passa P: Development of congestive heart failure in type 2 diabetic patients with microalbuminuria or proteinuria: observations from the DIABHYCAR (type 2 DIABetes, Hypertension, CArdiovascular Events and Ramipril) study. Diabetes Care 2003, 26(3):855-860.

32. de Zeeuw D, Remuzzi G, Parving HH, Keane WF, Zhang Z, Shahinfar S, Snapinn S, Cooper ME, Mitch WE, Brenner BM: Albuminuria, a therapeutic target for cardiovascular protection in type 2 diabetic patients with nephropathy. Circulation 2004 I I 0(8):92।-927.

33. Horwich TB, Fonarow GC, Hamilton MA, MacLellan WR, Woo MA Tillisch $\mathrm{J}$ : The relationship between obesity and mortality in patients with heart failure. J Am Coll Cardiol 200I, 38(3):789-795.

34. Bray GA: Health hazards of obesity. Endocrinol Metab Clin North Am 1996, 25(4):907-919.
35. Stevens RJ, Coleman RL, Adler Al, Stratton IM, Matthews DR, Holman RR: Risk factors for myocardial infarction case fatality and stroke case fatality in type 2 diabetes: UKPDS 66. Diabetes Care 2004, 27(I):20I-207.

36. King $\mathrm{H}$, Aubert RE, Herman WH: Global burden of diabetes, 1995-2025: prevalence, numerical estimates, and projections. Diabetes Care 1998, 2I(9):|4|4-|43|.
Publish with Biomed Central and every scientist can read your work free of charge

"BioMed Central will be the most significant development for disseminating the results of biomedical research in our lifetime. "

Sir Paul Nurse, Cancer Research UK

Your research papers will be:

- available free of charge to the entire biomedical community

- peer reviewed and published immediately upon acceptance

- cited in PubMed and archived on PubMed Central

- yours - you keep the copyright
Biomedcentral 